\title{
Graphene oxide incorporated polysulfone substrate for the fabrication of flat-sheet thin-film composite forward osmosis membranes
}

Myoung Jun Park ${ }^{\mathrm{a}}$, Sherub Phunstho ${ }^{\mathrm{a}}$, Tao He ${ }^{\mathrm{b}}$, Grace M. Nisola ${ }^{\mathrm{c}}$, Leonard D. Tijing ${ }^{\mathrm{a}}$, XueMei Li ${ }^{\mathrm{b}}$, Gang Chen ${ }^{\mathrm{b}}$, Wook-Jin Chung ${ }^{\mathrm{c}}$, Ho Kyong Shon ${ }^{\mathrm{a}, *}$

${ }^{a}$ Centre for Technology in Water and Wastewater, School of Civil and Environmental Engineering, University of Technology, Sydney (UTS), P.O. Box 123, 15 Broadway, NSW 2007, Australia

${ }^{b}$ Laboratory for Membrane Materials and Separation Technology, Shanghai Advanced Research Institute, Chinese Academy of Sciences, Shanghai 201203, China

${ }^{c}$ Energy and Environment Fusion Technology Center (E2 FTC), Department of Energy Science and Technology (DEST), Myongji University, Myongji-ro 116, Nam-dong, Cheoin-gu, Yongin-si, Gyeonggi-do 449-728, Republic of Korea

* Corresponding author Ho Kyong Shon Email: Hokyong.Shon-1@uts.edu.au; Tel.: +61 2 9514 2629; Fax: +61 295142633 . 


\section{Abstract}

The preparation and performances of the newly synthesized thin film composite (TFC) forward osmosis (FO) membranes with graphene oxide (GO)-modified support layer are presented in this study. GO nanosheets were incorporated in the polysulfone (PSf) to obtain PSf/GO composite membrane support layer. Polyamide (PA) active layer was subsequently formed on the PSf/GO by interfacial polymerization to obtain the TFC-FO membranes. Results reveal that at an optimal amount of GO addition (0.25 wt\%), a PSf/GO composite support layer with favorable structural property measured in terms of thickness, porosity and pore size can be achieved. The optimum incorporation of GO in the PSF support layer not only significantly improved water permeability but also allowed effective PA layer formation, in comparison to that of pure PSf support layer which had much lower water permeability. Thus, a TFC-FO membrane with high water flux $\left(19.77 \mathrm{Lm}^{-2} \mathrm{~h}^{-1}\right.$ against $6.08 \mathrm{Lm}^{-2} \mathrm{~h}^{-1}$ for pure PSf) and reverse flux selectivity (5.75 $\mathrm{Lg}^{-1}$ against $3.36 \mathrm{Lg}^{-1}$ for pure PSf) was obtained under the active layer facing the feed solution or AL-FS membrane orientation. Besides the improved structural properties (reduced structural parameter, S) of the support layer, enhanced support hydrophilicity also contributed to the improved water permeability of the membrane. Beyond a certain point of GO addition ( $\geq 0.5 \mathrm{wt} \%)$, the poor dispersion of GO in dope solution and significant structure change resulted in lower water permeation and weaker mechanical properties in support as well as FO flux/selectivity of consequent TFC membrane. Overall, this study suggests that GO modification of membrane supports could be a promising technique to improve the performances of TFC-FO membranes.

Keywords: graphene oxide, polysulfone, forward osmosis membrane, thin film composite, hydrophilic nanomaterial 


\section{Introduction}

The issues of water shortage and increasing water demand have become a serious problem globally due to rapid population growth and economic development. To solve this water crisis, seawater desalination is one of the most promising solutions to supply alternative water resources [1-3]. Recently, forward osmosis (FO) membrane technology has gained attention for various applications including desalination [4], wastewater treatment [5, 6], osmotic power generation [3, 7-9], pharmaceutical industry [10] and food processing [11]. Unlike the hydraulic pressure-driven RO process, the osmotic pressure gradient (i.e. generated by the draw solution) across a semi-permeable FO membrane induces the water transport. This is due to the relatively lower energy consumption and lower fouling propensity in the FO process as compared to the conventional reverse osmosis (RO) process [12, 13].

Current researches have focused on developing thin film composite (TFC) FO membranes as they exhibit higher water permeability and lower reverse solute permeability, especially compared to the commercially available cellulose triacetate (CTA) FO membranes (Hydration Technology Innovations Inc., HTI Co., USA) [14, 15]. A TFC-FO membrane is typically composed of a (1) thin active layer (i.e. polyamide) responsible for high salt rejection, and (2) subjacent porous structure as a mechanical support layer, for convenient water transport [14, 16-21]. Considering these TFC components, a more industrially-viable FO system can be attained by further improving the membrane capacity; one way to achieve this is through structural manipulation of the support layer. 
Incorporation of hydrophilic nanomaterials such as titanium dioxide $\left(\mathrm{TiO}_{2}\right)[16,22]$, modified carbon nanotubes [23], porous zeolite nanoparticles [24], and reduced graphene oxide modified graphitic carbon nitride [18] into the support layer of TFC-FO membranes has resulted in enhanced FO membrane performance by reduction in structural parameter (S). Particularly, the physical and structural modifications by these nanomaterials on the support layer resulted in increased hydrophilicity and/or porosity, which remarkably improved the water flux of the TFC-FO membranes and at the same time lowered the effect of internal concentration polarization (ICP) phenomenon in the FO membrane [25, 26].

Due to its unique properties, graphene oxide (GO) is an attractive material choice to modify the support layer of TFC-FO membranes. A two-dimensional (2D) single-layer GO nanosheet is typically one atomic thick (thickness $=1 \sim 2 \mathrm{~nm}$ ) and abundantly contains oxygenous functional groups such as carboxyl, epoxy and hydroxyl groups [27]. These properties offer great potential for making composite materials with unique structural properties, high chemical stability, strong hydrophilicity, and excellent antifouling properties [27-30]. Recent studies have used GO or modified GO as fillers for the fabrication of ultrafiltration composite membranes with improved hydrophilic and antifouling properties for wastewater treatment [28, 31-33]. To the best of our knowledge, the potential of GO nanosheets as fillers to modify the structure and surface properties of the TFC-FO support layer which subsequently reduce the $\mathrm{S}$ value has never been explored earlier.

In this study, GO nanosheets prepared via a modified Hummer's method [34, 35] were used as fillers to modify the polysulfone (PSf) support of TFC-FO membranes. A series of characterizations were conducted to understand the influence of GO on the structural property and surface hydrophilicity of the PSf support. PSf supports with varied GO loadings were prepared and tested to determine the most suitable support material composition for FO 
operation. Finally, FO experiments were performed to assess the performance of the most suitable TFC-FO membrane under two modes of membrane orientations with the active layer facing either the feed or the draw solution during operation.

\section{Experimental}

\subsection{Materials}

Graphite powder was purchased from Acros, Korea. Sulfuric acid $\left(\mathrm{H}_{2} \mathrm{SO}_{4}\right)$ and potassium permanganate $\left(\mathrm{KMnO}_{4}\right)$ were supplied from Junsei, whereas sodium nitrate $\left(\mathrm{NaNO}_{3}\right)$ and hydrogen peroxide $\left(\mathrm{H}_{2} \mathrm{O}_{2}\right)$ were supplied by Shinyo and Showa, respectively. Polysulfone (PSf, Udel P-3500) from Solvay Solexis, 1,2-phenylenediamine (MPD, 99\%) and trimesoyl chloride (TMC, 98\%) from Sigma-Aldrich were used for membrane fabrications. N,Ndimethylacetamide (DMAc, analytical grade), sodium chloride ( $\mathrm{NaCl})$ and n-hexane were purchased from Sinopharm Chemical Reagent Co., Ltd.

\subsection{Preparation of GO nanosheets}

The GO nanosheets were prepared according to a modified Hummer's method [34, 35]. Approximately $3 \mathrm{~g}$ graphite was dispersed in a $70 \mathrm{~mL}$ chilled (ice bath: $<20{ }^{\circ} \mathrm{C}$ ) $\mathrm{H}_{2} \mathrm{SO}_{4}$, which was vigorously stirred until homogenous dispersion was achieved. About $1.5 \mathrm{~g}$ of $\mathrm{NaNO}_{3}$ was subsequently added and stirred for $10 \mathrm{~min}$, followed by addition of $9 \mathrm{~g} \mathrm{KMnO}_{4}$ (slow addition due to highly exothermic reaction). The reaction was kept at $40^{\circ} \mathrm{C}$ for 30 min before adding $150 \mathrm{~mL}$ deionized (DI) and heating the reactor at $95^{\circ} \mathrm{C}$. After $15 \mathrm{~min}, 1 \mathrm{~L} \mathrm{DI}$ was poured followed by dropwise addition of $15 \mathrm{~mL} \mathrm{H}_{2} \mathrm{O}_{2}$. While still warm, the reacted 
dispersion was vacuum filtered to avoid precipitation of mellitic acid. The filtered cake was rinsed with $10 \mathrm{wt} \% \mathrm{HCl}$ solution to remove unreacted residues. The cake was re-dispersed and sonicated for $1 \mathrm{~h}$ in $400 \mathrm{~mL} 10 \mathrm{wt} \% \mathrm{HCl}$ solution and then centrifuged (5000 rpm, 30 min) to collect the expanded graphite. This step was performed twice and then was repeated using $400 \mathrm{~mL}$ DI water at longer sonication period (18 h). After several times of dispersion and sonication in DI, the dispersion was transferred in dialysis bags (Spectra/Por 2, Spectrum Laboratories, Inc. CA, USA) then immersed in $5 \mathrm{~L}$ DI water to remove residual acids. The DI water was replaced every two hours and the dialysis was conducted for at least one week. The dialyzed samples were transferred in a flask and then sonicated for $1 \mathrm{~h}$. The dispersion was centrifuged (3000 rpm, $40 \mathrm{~min}$ ) and the upper $75 \%$ of the supernatant was retrieved as the final GO dispersion. Dried GO sheets were obtained through vacuum evaporation of the dispersion.

\subsection{Preparation of PSf/GO support layer}

All PSf/GO substrates were fabricated by conventional phase inversion technique. Known amounts of dried GO sheets were first homogenously dispersed in DMAc via ultra-sonication. Next, the PSf pellets were added under vigorous stirring at $65^{\circ} \mathrm{C}$ to obtain $18 \mathrm{wt} \%$ PSf with varied GO loading (0, 0.1, 0.25, 0.5 and $1.0 \mathrm{wt} \%)$ with respect to PSf amount. Polymer viscosities (average of three measurements) were determined at $30^{\circ} \mathrm{C}$ by a rotational viscometer (Brookfield DV-II+ Pro Viscometer) at different shear rates (0 to $17 \mathrm{~s}^{-1}$ ) and rotation speeds (2.5 to $50 \mathrm{rpm}$ ). Before fabrication, all PSf/GO solutions were de-gassed at $30^{\circ} \mathrm{C}$. The bubble-free solutions were then poured on glass plates and then spread into films using a casting machine (Elcometer 4340, Elcometer Aisa Pte Led) pre-set with $150 \mu \mathrm{m}$ gap. The nascent films were immersed in a water coagulation bath $\left(30^{\circ} \mathrm{C}\right)$ and then soaked in DI water for one day to completely remove the residual solvents. 


\subsection{Preparation of TFC-FO membranes by interfacial polymerization}

The dense active layer of polyamide was formed on one side of the PSf or PSf/GO surface through an interfacial polymerization method [36, 37]. Before each soaking step, excess solvents were removed from the membranes using an air knife. From the water bath, the membranes were placed in $2 \mathrm{wt} \%$ MPD aqueous solution for $2 \mathrm{~min}$ and then in $0.15 \mathrm{wt} \%$ TMC/n-hexane solution for $1 \mathrm{~min}$. After draining the excess TMC solution, the membranes were air-dried for $2 \mathrm{~min}$ and then oven-dried at $100^{\circ} \mathrm{C}$ for $3 \mathrm{~min}$. The prepared TFC membranes were subsequently preserved in DI water until it was tested. The prepared TFCFO composite membranes were denoted as GOT-0, GOT-0.1, GOT-0.25, GOT-0.5 and GOT1.0, corresponding to the membrane supports GO-0, GO-0.1, GO-0.25, GO-0.5 and GO-1.0, which contain $0,0.1,0.25,0.5$ and $1.0 \mathrm{wt} \%$ GO loading (weight ratio to the PSf), respectively.

\subsection{Characterization}

\subsubsection{GO characterization}

Oxygenous groups on prepared GO nanosheets were examined by attenuated total reflectance-Fourier transform infrared spectroscopy (ATR-FTIR, Varian 2000). Hydrophilic $\mathrm{COOH}$ and $\mathrm{OH}$ groups were quantified via modified Boehm titration as detailed elsewhere [38, 39]. The structure of GO nanosheets was examined under a transmission electron microscope (TEM, JEOL ARM 200F, Japan) at $100 \mathrm{kV}$.

\subsubsection{Membrane characterization}

The morphologies of PSf, PSf/GO supports and PSf/GOT membranes were observed in field emission scanning electron microscope (FE-SEM) (Zeiss Supra 55VP, Carl Zeiss AG) operated at $10 \mathrm{kV}$. For the examination of membrane cross-section, the samples were fractured in liquid nitrogen $\left(\mathrm{N}_{2}\right)$; all samples were sputtered with carbon source for 
observation. Atomic force microscopy (AFM) images were obtained from a Dimension 3100 Scanning Probe Microscope (Bruker) under tapping mode (scanning area of $5 \mu \mathrm{m} \times 5 \mu \mathrm{m}$ ). Surface properties of PSf/GO were characterized in terms of hydrophilicity; water contact angle measurements were done using an optical tensiometer (Theta Lite 100) equipped with an image processing software. The contact angle values are average of at least five measurements. Capillary flow porometry (Porolux 100) was used for the pore size determination and for the $\mathrm{N}_{2}$ gas permeability experiments. The pore size of PSf/GO was determined by analyzing dried samples under dry-up/wet-up mode using a wetting agent (Porefil surface tension: 16 dynes $\mathrm{cm}^{-1}$ ). For the gas permeability $\left(\mathrm{Lmin}^{-1}\right.$ ) experiment, $\mathrm{N}_{2}$ was supplied as a feed gas ranged from 0 to 28 bar in dry membrane samples at the same effective membrane area $\left(0.79 \mathrm{~cm}^{2}\right)$. Membrane porosity $(\varepsilon)$ was determined via gravimetric analysis using Eq. (1) given the density of water $\left(\rho_{w}=1.00 \mathrm{~g} \mathrm{~cm}^{-3}\right)$ and PSf $\left(\rho_{p}=1.24 \mathrm{~g} \mathrm{~cm}^{-3}\right)$.

Dried circular samples $\left(A=4.91 \mathrm{~cm}^{2}\right)$ were initially weighed $\left(\mathrm{m}_{2}, \mathrm{~g}\right)$ then were soaked in water for $24 \mathrm{~h}$ at $30^{\circ} \mathrm{C}$. Residual water was removed and then the wet samples were reweighed $\left(\mathrm{m}_{1}, \mathrm{~g}\right)$. Reported results are average values of at least five measurements.

$$
\varepsilon=\frac{\left(m_{1}-m_{2}\right) / \rho_{w}}{\left(m_{1}-m_{2}\right) / \rho_{w}+m_{2} / \rho_{p}}
$$

Mechanical strengths were quantified using Advanced Materials Testing System (LS1, Lloyd instruments Ltd), equipped with a $1 \mathrm{kN}$ load cell, using membranes cut with dimensions: 30 $\mathrm{mm} \times 10 \mathrm{~mm}$. The thickness of the samples were determined using a digital micrometer and used to calculate the membrane cross sectional area. At least five measurements were performed at a cross-head speed of $10 \mathrm{~mm} / \mathrm{min}$ and the values were averaged.

\section{6. $R O$ experiment for pure water permeability and salt rejection determination}


Pure water permeability and salt rejection performance of PSf/GO and PSf/GOT membranes were measured using a cross-flow RO filtration system (Sterlitech Corporation) with an effective membrane area of $42 \mathrm{~cm}^{2}$. Pure water flux (PWF, $J$ ) of PSf/GO membranes was measured at different transmembrane pressure (TMP) from 1 to 5 bar. Prior to flux measurements, the membranes were pressurized with DI water at 5 bar for $1 \mathrm{~h}$ to eliminate the effect of membrane compaction and to obtain stable TMP. The PSf/GOT membranes were tested in cross-flow membrane permeation experiments operated at 10 bar with $1.5 \mathrm{~L}$ $\min ^{-1}\left(0.25 \mathrm{~m} \mathrm{~s}^{-1}\right)$ cross-flow rate. Pure water flux $\left(J_{w}\right)$, pure water permeability $(A)$ and salt rejection $(R)$ were calculated using Eqns. (2), (3) and (4), respectively. The salt permeability coefficient (B) in Eqn. (5) was calculated based on the solution-diffusion theory [40, 41]. Sampling was performed after the system stabilized at $25^{\circ} \mathrm{C}$ and $\mathrm{P}=10$ bar for $1 \mathrm{~h}$. For the

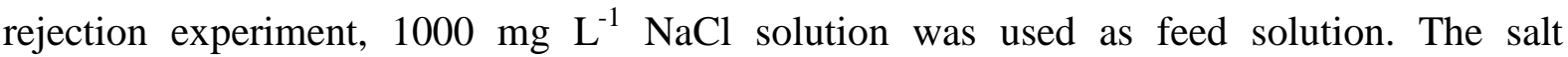
concentrations at the feed and permeate solutions were measured using a conductivity meter.

$$
\begin{aligned}
& J_{w}=\frac{\Delta V}{A_{m} \cdot \Delta t} \\
& A=\frac{J_{w}}{\Delta P}
\end{aligned}
$$

Where $\Delta V$ is the permeate volume, $\Delta t$ is the sampling time, $A_{m}$ is the effective membrane area in Eq. (2), and $\Delta P$ in Eq. (3) is the applied pressure while $C_{f}$ and $C_{p}$ in Eq. (4) are the salt concentrations at the feed and permeate solutions, respectively.

$$
\begin{aligned}
& R=\left(1-\frac{C_{p}}{C_{f}}\right) \times 100 \% \\
& B=J_{w} \frac{1-R}{R} \exp \left(-\frac{J_{w}}{k}\right)
\end{aligned}
$$


The mass transfer coefficient $(k)$ in Eq. (5) is a function of the Sherwood number (Sh), solute diffusion coefficient $(D)$, and hydraulic diameter $\left(d_{h}\right)$ of cross-flow cell as determined using Eq. (6). The Sherwood number is calculated based on the hydrodynamic conditions of the FO system using Eqs. (7) and (8) where Re is the Reynolds number, $S c$ is the Schmidt number and $L$ is the length of the channel [42, 43].

$k=\frac{S h \cdot D}{d_{h}}$

$$
\begin{aligned}
& S h=1.85\left(\operatorname{Re} \cdot S c \frac{d_{h}}{L}\right)^{0.33}(\operatorname{Re}<2000) \\
& S h=0.04\left(\operatorname{Re}^{0.75} \cdot S c^{0.33}\right) \quad(\operatorname{Re}>2000)
\end{aligned}
$$

\subsection{Forward osmosis tests}

The FO membrane cell with $0.4 \mathrm{~cm}$ depth has an effective membrane area of $30 \mathrm{~cm}^{2}$. Two variable speed gear pumps were used to circulate the feed and draw solutions concurrently. Flow rates of the feed and draw solutions were monitored with rotameters and kept constant at $1.8 \mathrm{~L} \mathrm{~min}^{-1}$ (cross flow velocity $=0.25 \mathrm{~m} \mathrm{~s}^{-1}$ ). The temperatures of the feed and draw solutions were kept at $25^{\circ} \mathrm{C}$. The membranes were tested under the FO mode (i.e., active layer facing feed solution or AL-FS) and pressure retarded osmosis (PRO) mode (i.e., active layer facing draw solution or AL-DS).

To evaluate the FO performance of the PSf/GOT membranes, $0.5 \mathrm{M} \mathrm{NaCl}$ was used as draw solution and DI water as feed. The change in salt concentration at the draw solution was marginal as the ratio of permeated water volume to that of the draw solution was less than $2 \%$ during FO operation. With DI as feed, salt leakage was calculated by measuring the conductivity change in the feed solution and re-calculated back to the salt concentration of 
the draw solution. An electronic balance (CP2002, Ohaus Instrument Co., Ltd.) connected to a computer was used to record the mass of permeated water $(m)$ into the draw solution. FO test was performed for at least $1 \mathrm{~h}$ to obtain stable measurements. The reported values were averages from calculated data taken in the last $30 \mathrm{~min}$ of operation. The FO flux $\left(J_{v}, \mathrm{~L} \mathrm{~m}^{-2} \cdot \mathrm{h}^{-1}\right)$ was calculated using Eq. (9) where $S_{m}$ is the effective membrane surface area.

$$
J_{v}=\frac{\Delta m}{S_{m} \cdot \Delta t \cdot \rho_{w}}
$$

Salt leakage from the draw solution or reverse salt diffusion $J_{s}\left(\mathrm{~g} \mathrm{~m}^{-2} \mathrm{~h}^{-1}\right)$ was calculated using Eq. (10) where $C_{t}$ is the salt concentration and $V_{t}$ is the feed volume at time t. Thus, the total amount of leaked salt to the feed solution is quantified as the change in $C_{t} V_{t}$ or $\Delta\left(C_{t} V_{t}\right)$ at time interval $\Delta t$.

$$
J_{s}=\frac{\Delta\left(C_{t} V_{t}\right)}{S_{m} \cdot \Delta t}
$$

\subsection{Determination of membrane structural parameter (S)}

Under AL-FS mode, solute resistivity $K$ was calculated using Eq. (11) where $\pi_{D, b}$ and $\pi_{F, m}$ are the osmotic pressures of the bulk draw solution and feed solution near the membrane surface, respectively [44]. The $\pi_{F, m}$ was determined using Eq. (12) where $\pi_{F, b}$ is the osmotic pressure of the bulk feed.

$$
K=\frac{1}{J_{v}} \ln \frac{B+\pi_{D, b}}{B+J_{v+\pi_{F, m}}}
$$

$$
\frac{\pi_{F, m}}{\pi_{F, b}}=\exp \left(\frac{J_{v}}{K}\right)
$$


Membrane structural parameter $S$ was calculated from the product of $K$ and solute diffusivity (D), which is equivalent to the product of membrane tortuosity $\tau$ and membrane thickness $t_{s}$, divided by the membrane porosity $\varepsilon$ as expressed in Eq. (13) [44].

$$
S=K D=\frac{\mathrm{t}_{\mathrm{s}} \tau}{\varepsilon}
$$

\section{Results and discussion}

\subsection{Characterization of GO}

The presence of oxygenous groups in GO was confirmed via FTIR (Fig. 1a). Compared to graphite which has a featureless spectrum, GO reveals several characteristic peaks attributable to $\mathrm{COOH}, \mathrm{OH}$ and epoxide groups [45, 46]. Peaks at $3425 \mathrm{~cm}^{-1}$ and $1404 \mathrm{~cm}^{-1}$ are due to the $\mathrm{O}-\mathrm{H}$ stretching and $\mathrm{O}-\mathrm{H}$ deformation, respectively [45]. The FTIR signal at $1720 \mathrm{~cm}^{-1}$ indicates the $\mathrm{C}=\mathrm{O}$ stretching of the carboxyl group $(\mathrm{COOH})$ whereas those at 1224 $\mathrm{cm}^{-1}$ and $1065 \mathrm{~cm}^{-1}$ are due to the C-O stretching of epoxy and alkoxy groups, respectively [45]. The peak at $1620 \mathrm{~cm}^{-1}$ for $\mathrm{C}=\mathrm{C}$ stretching suggests skeletal vibrations of unoxidized graphitic domains or the vibrations of the adsorbed water molecules on the sample [46]. Furthermore, the presence of oxygenous groups was quantified via Boehm titrations which reveal $25.33 \mathrm{mmol} \mathrm{g}^{-1}$ of acidic groups; from which $23.61 \mathrm{mmol} \mathrm{g}^{-1}$ are $\mathrm{COOH}$ while 1.72 mmol $\mathrm{g}^{-1}$ are $\mathrm{OH}$ groups. This indicates that the prepared GO was highly hydrophilic, which is a great pre-requisite for an additive of the PSf support for subsequent studies. TEM image (Fig. 1a) reveals the appearance of an ultra-thin GO nanosheet which indicates the successful chemical exfoliation of graphite via the modified Hummer's method [47].

$<<$ Insert Figure $1>>$ 


\subsection{GO presence in PSf substrates}

Visible evidence directly reveals the presence of golden brown GO nanosheets in the PSf substrates as shown in Fig. S1. The off-white pure PSf was gradually transformed into brownish color as GO content was increased in PSf/GO membranes. Elemental mapping of the membranes via EDS also indicates the presence of GO nanosheets in the PSf/GO (Fig. 1b). Relative to pure PSf, decrease in sulfur content was observed concomitant with the increase in oxygen level as more GO nanosheets were added in the membranes. The relatively higher oxygen content in PSf/GO originated from the oxygenous groups of the nanosheets. But as GO also contained carbon, carbon content was almost the same for all PSf/GO. This trend is consistent with the EDS results from an earlier work on GO containing membrane prepared with antifouling properties [28]. All of these results demonstrate the successful incorporation of GO in the PSf support.

\subsection{Effect of GO loading on PSf/GO supports}

\section{$<<$ Insert Figure $2>>$}

Addition of GO at 0.1 and $0.25 \%$ loading significantly increased the pure water permeability to 400 and $720 \mathrm{Lm}^{-2} \mathrm{~h}^{-1} \mathrm{bar}^{-1}$, respectively, in comparison to that of pure PSf (100 $\left.\mathrm{Lm}^{-2} \mathrm{~h}^{-1} \mathrm{bar}^{-1}\right)$ as shown in Fig 2a. However, further increase in GO loading to 0.5 and $1.0 \mathrm{wt} \%$ in fact reduced the water flux. It is known that enhancement of surface hydrophilicity due to GO addition could facilitate easier permeation of water through the support [27, 28]. Likewise, attainment of appropriate morphological and structural properties such as porosity, pore structure, tortuosity, and membrane thickness could reduce hydraulic resistance and favor higher convective motion of water through the membrane. Thus, to decouple the effects of surface energy and structural property changes induced by GO on the obtained pure water 
permeability trend of PSf/GO supports, several characterization and complementary experiments were performed.

\subsubsection{Effect of GO loading on the surface hydrophilicity of PSf/GO supports}

\section{$<$ Insert Figure $3>>$}

The water contact angle of pure PSf substrate was about $75^{\circ}$ (Fig. 3) but was reduced to as low as $62^{\circ}$ as the GO loading was increased up to $0.5 \mathrm{wt} \%$. This result is consistent with those from previous studies wherein composite membranes exhibited lower contact angles upon incorporation of hydrophilic nanomaterials as fillers [16, 22, 23, 28, 31, 33]. Thus, the abundant presence of oxygenous functional groups such as hydroxyl, carboxyl and epoxy groups in GO might have improved the membrane hydrophilicity which resulted in higher water permeability for the composite membrane. However, membrane hydrophilisation by GO was effective only to some extent as further increase in GO loading to $1.0 \mathrm{wt} \%$ slightly increased the contact angle to $70^{\circ}$. Moreover, as the pure water permeability trend is not fully consistent with that of contact angle results, the structural properties of the supports were further inspected to fully elucidate the effect of GO.

\subsubsection{Effect of GO loading on the structure of PSf/GO supports}

Fig. 4 reveals FE-SEM images of top and bottom surfaces as well as cross-section of membrane supports with different GO loadings. All membranes have typical asymmetric structures; the dense top surface of all samples had no open pores. Meanwhile, cross-section images reveal long finger-like macro-voids near the top whereas pores as large as $1 \mu \mathrm{m}$ are evident at the bottom section of the membranes. The morphology of pure PSf is characterized by the presence of few macrovoids which co-existed with sponge-like structure at the bottom section of the membrane. Meanwhile, GO loadings at 0.1 and $0.25 \mathrm{wt} \%$ resulted in 
membranes with larger finger-like pores and predominant presence of macrovoids at the bottom section with very minor presence of sponge-like structure. The increase in porosity and pore size as well as reduction in membrane thickness (Fig. 5) at this GO loading range is consistent with the FE-SEM observation. Thus, the higher pure water permeability strongly suggests that the resultant morphological characteristics imparted by the addition of low amount of GO $(\leq 0.25 \mathrm{wt} \%)$ promoted a less hindered transport of water through the membrane support. Due to its hydrophilicity, GO could increase the thermodynamic incompatibility between polymer and the solvent which often results in faster onset of phase inversion [18]. Moreover, addition of small amount of hydrophilic GO might have accelerated the entrance of water (non-solvent) into the membrane which ensured quicker exchange between the solvent and non-solvent. This occurrence suppressed the formation of sponge-like structures and favored the formation of larger finger-like voids, which resulted in membranes with higher porosity and larger pore sizes [18, 28].

\section{$<<$ Insert Figure $4>>$}

But as GO loading was further increased up to $1.0 \mathrm{wt} \%$, the sponge-like structures reappeared which could be due to two reasons. First, Fig. S2 illustrates no drastic change in polymer solution viscosity until $0.25 \mathrm{wt} \%$ GO loading. The more evident viscosity increase at GO loading $\geq 0.5 \mathrm{wt} \%$ might have retarded the demixing process between the solvent and non-solvent which decreased the phase-separation rate $[28,48]$. Relative to GO-0.25 wt\%, the kinetic hindrance in phase separation of membranes with higher GO loading might have promoted the formation of sponge-like structures over the finger-pores, which consequently resulted in less improvement of pure water permeability. This was also reflected by the lower porosity and pore diameter at $\mathrm{GO} \geq 0.5 \mathrm{wt} \%$ than those at lower loading (Fig. 5). Second, evidence of GO aggregation was observed at high GO loading as shown in Fig. S3 
(supplementary information). At $1.0 \mathrm{wt} \%$ GO loading, lateral pore structures were evident at the cross-section of the membrane. This occurrence was also documented by earlier studies when higher amount of GO were embedded in the membranes [31, 48]. It is probable that the remarkable increase in viscosity of polymer solution at GO loading $\geq 0.5 \mathrm{wt} \%$ has made it more difficult to disperse the nanosheets. Consequently, membranes with GO loading higher than $0.25 \mathrm{wt} \%$ showed less pronounced effect on the structural properties (Figs. 4 and 5) of the support which explains the pure water permeability trend in Fig. 2.

To further ascertain this finding, gas permeation $\left(\mathrm{N}_{2}\right)$ was also conducted to eliminate the surface property effect (i.e. hydrophilicity effect on water transport) of GO on pure water permeability. Fig. $2 \mathrm{~b}$ showed striking similarity of $\mathrm{N}_{2}$ gas volumetric flow rate with that of pure water flux trend (Fig. S4) which can be arranged in the sequence: GO-0.25 > GO-0.1 > GO-0.5 > GO-1.0 > pure PSf. This suggests that structural change imparted by hydrophilic GO has more influence on the water permeability properties of the membrane than that of the improved wettability.

\section{$<<$ Insert Figure $5>>$}

These findings eventually offer that the amount of GO that can be added in the PSf support must be optimized to maximize the enhancement in membrane performance. Specifically, the results herein highlight that more than the enhanced surface hydrophilicity effect of hydrophilic additives like GO, their influence on membrane formation can be exploited to manipulate the structural properties of the FO support which predominantly influenced the water permeability of the membrane.

\subsubsection{Mechanical properties}

$<<$ Insert Figure $6>>$ 
Fig. 6 shows the mechanical properties of PSf/GO membrane substrates at different GO loadings. The tensile strength and elongation at break of pure PSf was maintained up to 0.25 wt\% GO loading. The stable measurements indicate that low GO loading has no significant effect on the bulk mechanical property of PSf. However, further increase in GO loading from 0.5 to $1.0 \mathrm{wt} \%$ resulted in slightly lower tensile strength and more remarkable decrease in elongation at break. These results remain consistent with the dispersion of GO in PSf at various loadings. The comparable mechanical properties at low loading $(\leq 0.25 \mathrm{wt} \%)$ with that of pure PSf suggest well dispersion of GO nanosheets into the polymer matrix. However, excessive presence of GO ( $\geq 0.5 \mathrm{wt} \%)$ resulted in its aggregation that introduced some microdefects, which ultimately resulted to mechanically weaker membranes [28, 49, 50].

\subsection{Effect of GO incorporation for TFC-FO membranes}

\subsubsection{Characteristic and RO performance of TFC-FO membranes}

FE-SEM images in Fig. 7 show the ridge-and-valley structures on the surface and near the top cross-section of the prepared TFC-FO membranes, which indicate the presence of polyamide (PA) layer formed via interfacial polymerization [51]. Compared to the TFC membrane with pure PSf support, all TFCs prepared from PSf/GO with varied GO loadings have thinner top cross-section.

\section{$<<$ Insert Figure $7>>$ \\ $<<$ Insert Table 1 >>}

From cross-flow RO operation results listed in Table 1, GOT-0 had pure water permeability of $A=0.91 \mathrm{Lm}^{-2} \mathrm{~h}^{-1} \mathrm{bar}^{-1}$. Except GOT-1.0, all GOT membranes with GO nanosheets had higher $A$ values than that of GOT-0. In fact, the trend of $A$ values is consistent with that of pure water permeability of PSf/GO substrate wherein the highest $A=1.76 \mathrm{Lm}^{-2} \mathrm{~h}^{-1} \mathrm{bar}^{-1}$ was 
obtained from GOT-0.25. Likewise, highest salt rejection of $\mathrm{R}=98.7 \%$ was obtained from GOT-0.25 which explains the lowest salt permeability $(B=0.11$ bar) from this TFC-FO membrane. Among the FO membranes prepared, GOT-0.25 had the highest separation efficiency as it exhibited the lowest $B / A$ value. A low $B / A$ is favorable as it directly suggests low reverse solute diffusion from draw solution to the feed and therefore, low propensity to fouling caused by solute accumulation in FO systems [14]. The lower salt rejections in other TFC membranes maybe due to the ineffective PA layer formation, especially at higher GO loading $\geq 0.5 \mathrm{wt} \%$.

\section{$<$ Insert Figure $8>>$}

\section{$<<$ Insert Table $2>>$}

The observed trends on salt rejection and salt permeability from RO operation were elucidated in terms of the surface roughness of the membrane supports via AFM (Fig. 8). The results reveal the broad asperities on pure PSf surface, with mean roughness $R_{a}=14 \mathrm{~nm}$, root mean square ridge elevations $R_{m s}=17.56 \mathrm{~nm}$, and maximum ridge elevation $R_{\max }=30.45 \mathrm{~nm}$ (Table 2). Meanwhile, addition of GO resulted in sharper and denser asperities on PSf/GO supports than that of pure PSf [31, 32]. Nonetheless, based on $R_{a}, R_{m s}$ and $R_{\max }$ values, the roughness properties of PSf/GO declined as GO loading were increased to $0.25 \mathrm{wt} \%$ and then increased again at $\geq 0.5 \mathrm{wt} \%$ loadings. This indicates that well-dispersed GO could smoothen the surface of PSf/GO, which was most remarkable in GO-0.25 [52]. This characteristic could be most favorable for the formation of PA layer via interfacial polymerization, which positively influenced the salt rejection performance of GOT-0.25 [18]. On the other hand, GO aggregation at higher loading might have contributed on the surface roughness of the support which reduced the interfacial polymerization efficiency and thereby negatively affected the salt rejection ability of GOT-0.5 and GOT-1.0 membranes [16, 22]. Meanwhile, the higher 
salt rejection of GOT-0 than that of GOT-0.1 could be explained as follows. While GOT-0 had rougher surface than GOT-0.1 based on R values, the asperities were broad (Fig. 8) which might not have significantly reduced the contact area of reaction for interfacial polymerization. This indicates that PA layer formation efficiency via interfacial polymerization could not be solely related to $\mathrm{R}$ values but also on the density and morphology of the asperities.

\subsubsection{Effect of GO loading on FO performance}

The TFC-FO membranes with different GO loadings were operated under AL-FS and AL-DS modes using $0.5 \mathrm{M} \mathrm{NaCl}$ draw solution and DI water as feed (Fig. 9). In AL-DS mode, concentrative ICP is considered negligible since DI water was used as feed. On the other hand, AL-FS mode experienced dilutive ICP which reduces the osmotic pressure gradient within the support layer. This explains the lower flux values of all membranes operated under AL-FS mode (at all GO loadings) than those operated under AL-DS (Fig. 9a) [37]. Meanwhile, the higher $J_{s}$ values obtained under AL-DS mode might be due to higher concentration differences across the membrane as indicated by the higher $J_{v}$ values (Fig. 9b) than those under AL-FS mode [44].

Regardless of the mode of operation, the $J_{v}$ trend with respect to GO loading was similar with that of pure water permeability (RO mode Fig. 2). Under both modes of operational-FS, $J_{v}$ significantly improved at 0.1 and 0.25 wt\% GO additions relative to GOT-0, despite the low osmotic pressure gradient $(0.5 \mathrm{M} \mathrm{NaCl})$. Relative to GOT-0, the highest improvement in $J_{v}$ was measured at GOT-0.25 for AL-FS (from 6.08 to $19.77 \mathrm{Lm}^{-2} \mathrm{~h}^{-1}$ ) and AL-DS modes (from 15.73 to $40.50 \mathrm{Lm}^{-2} \mathrm{~h}^{-1}$ ). Thus, the favorable structural changes in the support induced upon addition of $0.25 \mathrm{wt} \%$ GO (as explained in Section 3.3.2) also positively affected the FO performance of TFC-FO membranes [22, 53, 54]. 
These findings were further confirmed by the $\mathrm{S}$ values (Table 1) calculated from the RO and FO performance data. Results indicate that an optimal amount of GO addition (0.25 wt\%,) led to the lowest S value of $191 \mu \mathrm{m}$ among all tested membranes. Similarly, it exhibited the lowest tortuosity $(\tau)$ value (Table 1 ), which suggests that addition at $0.25 \mathrm{wt} \%$ GO has led to the formation of PSf/GO support with the shortest diffusive path length resulting in the most convenient transport of water through the membrane.

Meanwhile, $J_{s}$ values also increased with GO contents in the membrane substrates. While $J_{v}$ is expected to be directly related with $J_{s}$, the results at GOT-0.25 deviated from this relation. Albeit GOT-0.25 exhibited the highest $J_{v}$, moderate $J_{s}$ was obtained relative to other membranes. However, the reverse flux selectivity $\left(J_{v} / J_{s}\right)$ (Fig. 9c), defined as the volume of water produced per the moles (or mass) of draw solute lost was observed highest at GOT0.25 indicating that at this GO loading the modified PSf support layer is most favorable for the formation of PA active layer since $J_{v} / J_{s}$ value is independent of DS properties and structural parameter $[37,55]$. This result is consistent with the ability of the active PA layer to reject salts wherein as discussed in Section 3.4.1, the highest rejection was achieved by PSf/GO with $0.25 \mathrm{wt} \%$ loading. Meanwhile, the ineffective formation of PA layer at GO loadings $(\geq 0.5 \mathrm{wt} \%)$ could explain the low selectivity or $J_{v} / J_{S}$ values of the corresponding TFC-FO membranes.

$<<$ Insert Figure $9>>$

\subsection{Effect of NaCl draw solution concentrations with DI water and seawater as feed solutions}

The performance of GOT-0.25 TFC-FO membrane was conducted under AL-FS mode to study the effect of draw solution concentration $(0.5$ - 4.0 M NaCl). With DI water as feed, results in Fig. 10a reveal the steady increase in water flux from 19.77 to $43.68 \mathrm{Lm}^{-2} \mathrm{~h}^{-1}$ as the osmotic driving force increased with draw solution salt concentration. Meanwhile, increase in 
$J_{s}$ values can be ascribed to the similar increase in salt concentration gradient across the active layer of GOT-0.25 FO membrane [18]. However, the $J_{v} / J_{s}$ value remains fairly constant and this is expected given that its value is independent of DS concentrations as described in the previous section 3.4.2 [37, 55].

\section{$<<$ Insert Figure $10>>$}

Using $3.5 \mathrm{wt} \%(0.6 \mathrm{M})$ of $\mathrm{NaCl}$ as simulated seawater feed solution, the GOT-0.25 FO membrane exhibited $J_{v}=6.65 \mathrm{Lm}^{-2} \mathrm{~h}^{-1}$ at $1 \mathrm{M} \mathrm{NaCl}$ draw solution (Fig. 10b) which significantly increased to $25.31 \mathrm{Lm}^{-2} \mathrm{~h}^{-1}$ at $4 \mathrm{M} \mathrm{NaCl}$ draw solution.

Overall FO performance of GOT-0.25 is quite comparable with previous studies which also incorporated hydrophilic nanomaterials in membrane substrates such as $\mathrm{TiO}_{2}$ [22], zeolite [24] and carbon nanotube [23]. But the facile and efficient preparation steps for GO-modified supports could be a viable option to produce TFC-FO membranes with enhanced water flux and selectivity performances.

\section{Conclusions}

In this study, incorporation of GO nanosheets in the PSf support successfully enhanced the FO performance of the TFC-FO membrane. Results reveal that a small but optimal amount of added GO (0.25 wt\%) resulted in improved structural properties within the support layer, significantly enhancing the water permeability of the PSf/GO supported TFC-FO membrane. Regardless of the modes of membrane orientations, this PSf/GO supported TFC FO membrane at optimum GO loading exhibited the highest membrane selectivity. On the other hand, further increase in GO loadings beyond $0.5 \mathrm{wt} \%$ on PSf substrate resulted in less favorable structural properties of the support which directly affect water permeability and PA 
rejection layer formation due to ineffective or non-homogenous dispersion of GO in the PSf which resulted in the formation of membrane with sponge-like support structures with less porosity and smaller pore size. Non-homogeneous distribution of GO at higher loading also resulted in inefficient formation of PA selective layer via interfacial polymerization adversely affecting the salt rejection property of PSf/GO supported TFC-FO membranes. Nonetheless, the overall results in this study demonstrate that, the GO-modified PSf support layer could be a promising technique to produce TFC-FO membranes with enhanced water flux and flux selectivity.

\section{Acknowledgement}

This research was supported by a grant from the Australian Research Council (ARC) Discovery Projects (DP140100835), Natural Science Foundation of China (21176119), and the National Research Foundation of Korea (NRF) grant funded by the Ministry of Science, ICT \& Future Planning (No. 2012R1A2A1A01009683).

\section{References}

[1] M.A. Shannon, P.W. Bohn, M. Elimelech, J.G. Georgiadis, B.J. Marinas, A.M. Mayes, Science and technology for water purification in the coming decades, Nature, 452 (2008) 301-310.

[2] H.-S.L. Geoffrey M. Geise, Daniel J. Miller, Benny D. Freeman, James E. Mcgrath, Donald R. Paul, Water Purification by Membranes: The Role of Polymer Science, Journal of polymer science: Part B: Polymer physics, 48 (2010) 1685-1718.

[3] T.-S. Chung, S. Zhang, K.Y. Wang, J. Su, M.M. Ling, Forward osmosis processes: Yesterday, today and tomorrow, Desalination, 287 (2012) 78-81. 
[4] T.-S. Chung, X. Li, R.C. Ong, Q. Ge, H. Wang, G. Han, Emerging forward osmosis (FO) technologies and challenges ahead for clean water and clean energy applications, Current Opinion in Chemical Engineering, 1 (2012) 246-257.

[5] T.Y. Cath, D. Adams, A.E. Childress, Membrane contactor processes for wastewater reclamation in space, Journal of Membrane Science, 257 (2005) 111-119.

[6] R.W. Holloway, A.E. Childress, K.E. Dennett, T.Y. Cath, Forward osmosis for concentration of anaerobic digester centrate, Water research, 41 (2007) 4005-4014.

[7] A. Achilli, A.E. Childress, Pressure retarded osmosis: From the vision of Sidney Loeb to the first prototype installation — Review, Desalination, 261 (2010) 205-211.

[8] Q. She, X. Jin, C.Y. Tang, Osmotic power production from salinity gradient resource by pressure retarded osmosis: Effects of operating conditions and reverse solute diffusion, Journal of Membrane Science, 401-402 (2012) 262-273.

[9] N.Y. Yip, A. Tiraferri, W.A. Phillip, J.D. Schiffman, L.A. Hoover, Y.C. Kim, M. Elimelech, Thin-film composite pressure retarded osmosis membranes for sustainable power generation from salinity gradients, Environmental science \& technology, 45 (2011) 43604369.

[10] Q. Yang, K.Y. Wang, T.-S. Chung, A novel dual-layer forward osmosis membrane for protein enrichment and concentration, Separation and Purification Technology, 69 (2009) 269-274.

[11] E.M. Garcia-Castello, J.R. McCutcheon, Dewatering press liquor derived from orange production by forward osmosis, Journal of Membrane Science, 372 (2011) 97-101.

[12] L. Chekli, S. Phuntsho, H.K. Shon, S. Vigneswaran, J. Kandasamy, A. Chanan, A review of draw solutes in forward osmosis process and their use in modern applications, Desalination and Water Treatment, 43 (2012) 167-184. 
[13] S. Phuntsho, H.K. Shon, T. Majeed, I. El Saliby, S. Vigneswaran, J. Kandasamy, S. Hong, S. Lee, Blended fertilizers as draw solutions for fertilizer-drawn forward osmosis desalination, Environmental science \& technology, 46 (2012) 4567-4575.

[14] J. Wei, C. Qiu, C.Y. Tang, R. Wang, A.G. Fane, Synthesis and characterization of flatsheet thin film composite forward osmosis membranes, Journal of Membrane Science, 372 (2011) 292-302.

[15] J.M.C. Puguan, H.-S. Kim, K.-J. Lee, H. Kim, Low internal concentration polarization in forward osmosis membranes with hydrophilic crosslinked PVA nanofibers as porous support layer, Desalination, 336 (2014) 24-31.

[16] D. Emadzadeh, W.J. Lau, T. Matsuura, M. Rahbari-Sisakht, A.F. Ismail, A novel thin film composite forward osmosis membrane prepared from PSf-TiO2 nanocomposite substrate for water desalination, Chemical Engineering Journal, 237 (2014) 70-80.

[17] N. Widjojo, T.-S. Chung, M. Weber, C. Maletzko, V. Warzelhan, A sulfonated polyphenylenesulfone (sPPSU) as the supporting substrate in thin film composite (TFC) membranes with enhanced performance for forward osmosis (FO), Chemical Engineering Journal, 220 (2013) 15-23.

[18] Y. Wang, R. Ou, H. Wang, T. Xu, Graphene oxide modified graphitic carbon nitride as a modifier for thin film composite forward osmosis membrane, Journal of Membrane Science, 475 (2015) 281-289.

[19] N.N. Bui, J.R. McCutcheon, Hydrophilic nanofibers as new supports for thin film composite membranes for engineered osmosis, Environmental science \& technology, 47 (2013) 1761-1769.

[20] G. Han, S. Zhang, X. Li, N. Widjojo, T.-S. Chung, Thin film composite forward osmosis membranes based on polydopamine modified polysulfone substrates with enhancements in both water flux and salt rejection, Chemical Engineering Science, 80 (2012) 219-231. 
[21] N.-N. Bui, M.L. Lind, E.M.V. Hoek, J.R. McCutcheon, Electrospun nanofiber supported thin film composite membranes for engineered osmosis, Journal of Membrane Science, 385386 (2011) 10-19.

[22] D. Emadzadeh, W.J. Lau, T. Matsuura, A.F. Ismail, M. Rahbari-Sisakht, Synthesis and characterization of thin film nanocomposite forward osmosis membrane with hydrophilic nanocomposite support to reduce internal concentration polarization, Journal of Membrane Science, 449 (2014) 74-85.

[23] Y. Wang, R. Ou, Q. Ge, H. Wang, T. Xu, Preparation of polyethersulfone/carbon nanotube substrate for high-performance forward osmosis membrane, Desalination, 330 (2013) 70-78.

[24] N. Ma, J. Wei, S. Qi, Y. Zhao, Y. Gao, C.Y. Tang, Nanocomposite substrates for controlling internal concentration polarization in forward osmosis membranes, Journal of Membrane Science, 441 (2013) 54-62.

[25] R.C. Ong, T.-S. Chung, J.S. de Wit, B.J. Helmer, Novel cellulose ester substrates for high performance flat-sheet thin-film composite (TFC) forward osmosis (FO) membranes, Journal of Membrane Science, 473 (2015) 63-71.

[26] G. Han, T.-S. Chung, M. Toriida, S. Tamai, Thin-film composite forward osmosis membranes with novel hydrophilic supports for desalination, Journal of Membrane Science, 423-424 (2012) 543-555.

[27] M. Hu, B. Mi, Enabling graphene oxide nanosheets as water separation membranes, Environmental science \& technology, 47 (2013) 3715-3723.

[28] J. Lee, H.-R. Chae, Y.J. Won, K. Lee, C.-H. Lee, H.H. Lee, I.-C. Kim, J.-m. Lee, Graphene oxide nanoplatelets composite membrane with hydrophilic and antifouling properties for wastewater treatment, Journal of Membrane Science, 448 (2013) 223-230.

[29] B. Mi, Graphene Oxide Membranes for Ionic and Molecular Sieving, Science, 343 (2014) 740-742. 
[30] F. Perreault, M.E. Tousley, M. Elimelech, Thin-Film Composite Polyamide Membranes Functionalized with Biocidal Graphene Oxide Nanosheets, Environmental Science \& Technology Letters, 1 (2014) 71-76.

[31] S. Zinadini, A.A. Zinatizadeh, M. Rahimi, V. Vatanpour, H. Zangeneh, Preparation of a novel antifouling mixed matrix PES membrane by embedding graphene oxide nanoplates, Journal of Membrane Science, 453 (2014) 292-301.

[32] H. Zhao, L. Wu, Z. Zhou, L. Zhang, H. Chen, Improving the antifouling property of polysulfone ultrafiltration membrane by incorporation of isocyanate-treated graphene oxide, Physical chemistry chemical physics : PCCP, 15 (2013) 9084-9092.

[33] Z. Xu, J. Zhang, M. Shan, Y. Li, B. Li, J. Niu, B. Zhou, X. Qian, Organosilanefunctionalized graphene oxide for enhanced antifouling and mechanical properties of polyvinylidene fluoride ultrafiltration membranes, Journal of Membrane Science, 458 (2014) $1-13$.

[34] W.S. Hummers, R.E. Offeman, Preparation of Graphitic Oxide, National Lead Company, (1958).

[35] A.M. Dimiev, J.M. Tour, Mechanism of Graphene Oxide Formation, ACS NANO, 8 (2014) 3060-3068.

[36] G. Chen, Z. Wang, L.D. Nghiem, X.-M. Li, M. Xie, B. Zhao, M. Zhang, J. Song, T. He, Treatment of shale gas drilling flowback fluids (SGDFs) by forward osmosis: Membrane fouling and mitigation, Desalination, (2015).

[37] P. Xiao, L.D. Nghiem, Y. Yin, X.-M. Li, M. Zhang, G. Chen, J. Song, T. He, A sacrificial-layer approach to fabricate polysulfone support for forward osmosis thin-film composite membranes with reduced internal concentration polarisation, Journal of Membrane Science, 481 (2015) 106-114.

[38] S.L. Goertzen, K.D. Thériault, A.M. Oickle, A.C. Tarasuk, H.A. Andreas, Standardization of the Boehm titration. Part I. CO2 expulsion and endpoint determination, Carbon, 48 (2010) 1252-1261. 
[39] A.M. Oickle, S.L. Goertzen, K.R. Hopper, Y.O. Abdalla, H.A. Andreas, Standardization of the Boehm titration: Part II. Method of agitation, effect of filtering and dilute titrant, Carbon, 48 (2010) 3313-3322.

[40] C.Y. Tang, Q. She, W.C.L. Lay, R. Wang, A.G. Fane, Coupled effects of internal concentration polarization and fouling on flux behavior of forward osmosis membranes during humic acid filtration, Journal of Membrane Science, 354 (2010) 123-133.

[41] X. Jin, C.Y. Tang, Y. Gu, Q. She, S. Qi, Boric acid permeation in forward osmosis membrane processes: modeling, experiments, and implications, Environmental science \& technology, 45 (2011) 2323-2330.

[42] C.H. Tan, H.Y. Ng, Revised external and internal concentration polarization models to improve flux prediction in forward osmosis process, Desalination, 309 (2013) 125-140.

[43] C.H. Tan, H.Y. Ng, Modified models to predict flux behavior in forward osmosis in consideration of external and internal concentration polarizations, Journal of Membrane Science, 324 (2008) 209-219.

[44] T.Y. Cath, M. Elimelech, J.R. McCutcheon, R.L. McGinnis, A. Achilli, D. Anastasio, A.R. Brady, A.E. Childress, I.V. Farr, N.T. Hancock, J. Lampi, L.D. Nghiem, M. Xie, N.Y. Yip, Standard Methodology for Evaluating Membrane Performance in Osmotically Driven Membrane Processes, Desalination, 312 (2013) 31-38.

[45] S. Bose, T. Kuila, A.K. Mishra, N.H. Kim, J.H. Lee, Dual role of glycine as a chemical functionalizer and a reducing agent in the preparation of graphene: an environmentally friendly method, Journal of Materials Chemistry, 22 (2012) 9696.

[46] H.-L. Guo, X.-F. Wang, Q.-Y. Qian, F.-B. Wang, X.-H. Xia, A green approach to the synthesis of graphene nanosheets, ACS NANO, 3 (2009) 2653-2659.

[47] D.C. Marcano, D.V. Kosynkin, J.M. Berlin, A. Sinitskii, Z. Sun, A. Slesarev, L.B. Alemany, W. Lu, J.M. Tour, Improved Synthesis of Graphene Oxide, ACS NANO, 4 (2010) 4806-4814. 
[48] Y.T.L. M. L. Yeow, K. Li, Morphological Study of Poly (vinylidene fluoride) Asymmetric Membranes: Effect of the Solvent, Additive, and Dope Temperature, Journal of Applied Polymer Science, 92 (2004) 1782-1789.

[49] L. Yu, Y. Zhang, B. Zhang, J. Liu, H. Zhang, C. Song, Preparation and characterization of HPEI-GO/PES ultrafiltration membrane with antifouling and antibacterial properties, Journal of Membrane Science, 447 (2013) 452-462.

[50] Z. Wang, H. Yu, J. Xia, F. Zhang, F. Li, Y. Xia, Y. Li, Novel GO-blended PVDF ultrafiltration membranes, Desalination, 299 (2012) 50-54.

[51] N. Ma, J. Wei, R. Liao, C.Y. Tang, Zeolite-polyamide thin film nanocomposite membranes: Towards enhanced performance for forward osmosis, Journal of Membrane Science, 405-406 (2012) 149-157.

[52] S. Qiu, L. Wu, X. Pan, L. Zhang, H. Chen, C. Gao, Preparation and properties of functionalized carbon nanotube/PSF blend ultrafiltration membranes, Journal of Membrane Science, 342 (2009) 165-172.

[53] A. Tiraferri, N.Y. Yip, W.A. Phillip, J.D. Schiffman, M. Elimelech, Relating performance of thin-film composite forward osmosis membranes to support layer formation and structure, Journal of Membrane Science, 367 (2011) 340-352.

[54] W.C.L. Lay, J. Zhang, C. Tang, R. Wang, Y. Liu, A.G. Fane, Factors affecting flux performance of forward osmosis systems, Journal of Membrane Science, 394-395 (2012) 151-168.

[55] W.A. Phillip, J.S. Yong, M. Elimelech, Reverse draw solute permeation in FO: Modeling and experiments, Environmental science \& technology, 44 (2010) 5170-5176. 


\section{Figure Captions}

Fig. 1. FTIR spectrum for (a) graphite and GO and (b) elemental proportions for membrane substrate surface conducted by EDS mapping.

Fig. 2. (a) Pure water permeability and (b) $\mathrm{N}_{2}$ gas permeability with different pressure applications of membrane substrates which incorporated different GO contents.

Fig. 3. Contact angle results at various GO loading contents with respect to the PSf amount.

Fig. 4. FE-SEM images of top and bottom surface and cross section area for membrane substrates.

Fig. 5. Effect of GO contents in membrane substrate on membrane porosity, pore diameter and thickness

Fig. 6. Mechanical properties (tensile strength and elongation at break) for membrane substrates.

Fig. 7. FE-SEM images of PA selective layer and cross section for TFC-FO membranes (GOT-0. 0.1, 0.25, 0.5, and 1.0).

Fig. 8. AFM images for membrane substrates, (a) GO-0, (b) GO-0.1, (c) GO-0.25, (d) GO1.0 .

Fig. 9. Effect of GO contents in membrane substrates for TFC-FO membrane performance (DI water as feed solution and $0.5 \mathrm{M} \mathrm{NaCl}$ as draw solution), (a) water flux ( $\mathrm{L} \mathrm{m}^{-2} \mathrm{~h}^{-1}, J_{v}$ ), (b) reverse salt flux $\left(\mathrm{g} \mathrm{m}^{-2} \mathrm{~h}^{-1}, J_{s}\right)$, (c) reverse flux selectivity $\left(\mathrm{L} \mathrm{g}^{-1}, J_{v} / J_{s}\right)$. 
Fig. 10. FO performance under AL-FS mode for GOT-0.25 at different concentration of $\mathrm{NaCl}$ $(0.5,1.0,2.0,3.0,4.0 \mathrm{M} \mathrm{NaCl})$ as draw solutions and, (a) DI water and (b) $3.5 \mathrm{wt} \% \mathrm{NaCl}$ (model seawater, 0.6 M) as feed solutions. 


\section{Table Captions}

Table 1. Effect of GO loading on the membrane performance for TFC-FO membranes.

Table 2. Surface roughness of membrane substrates via AFM analysis. 

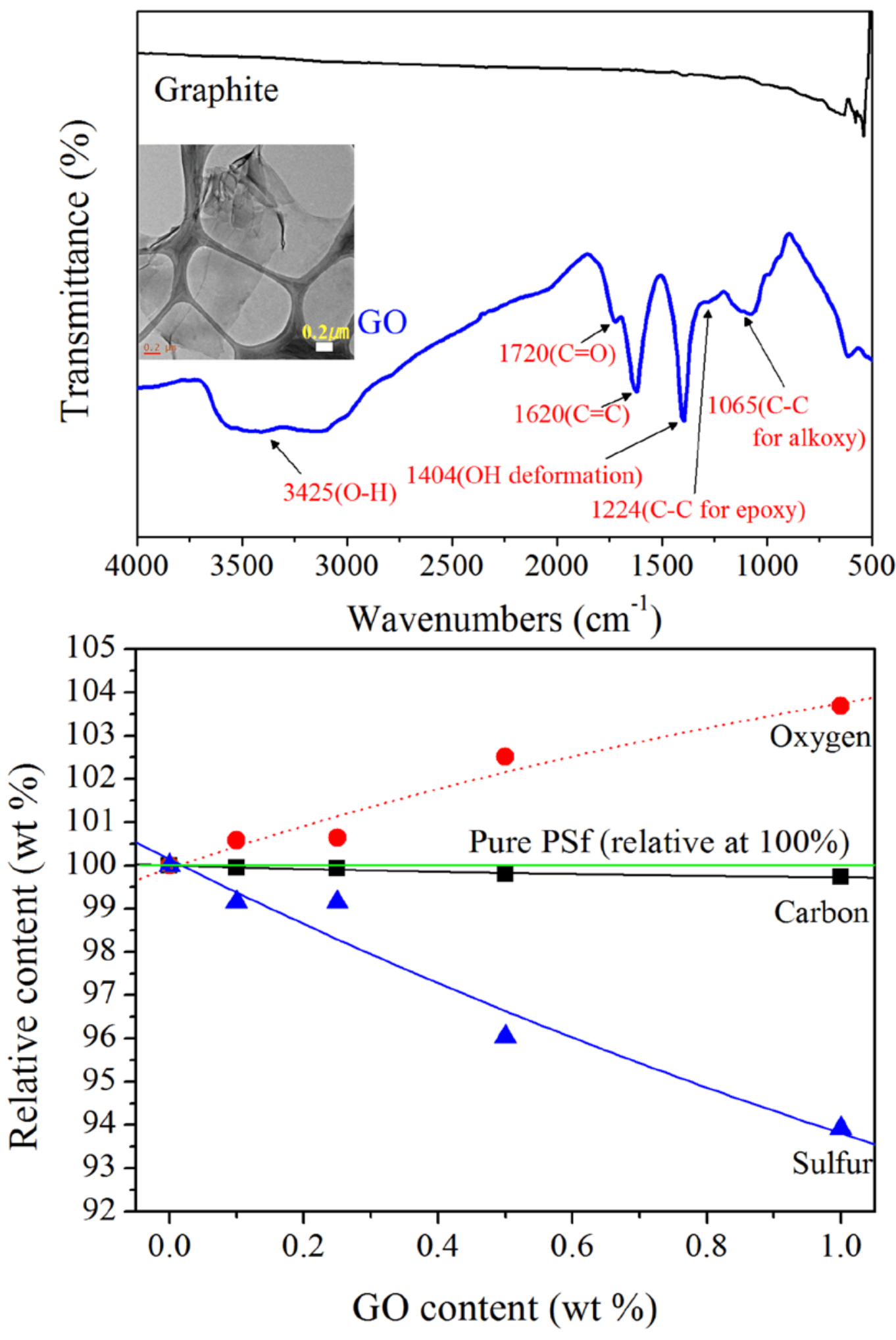

Figure 1 

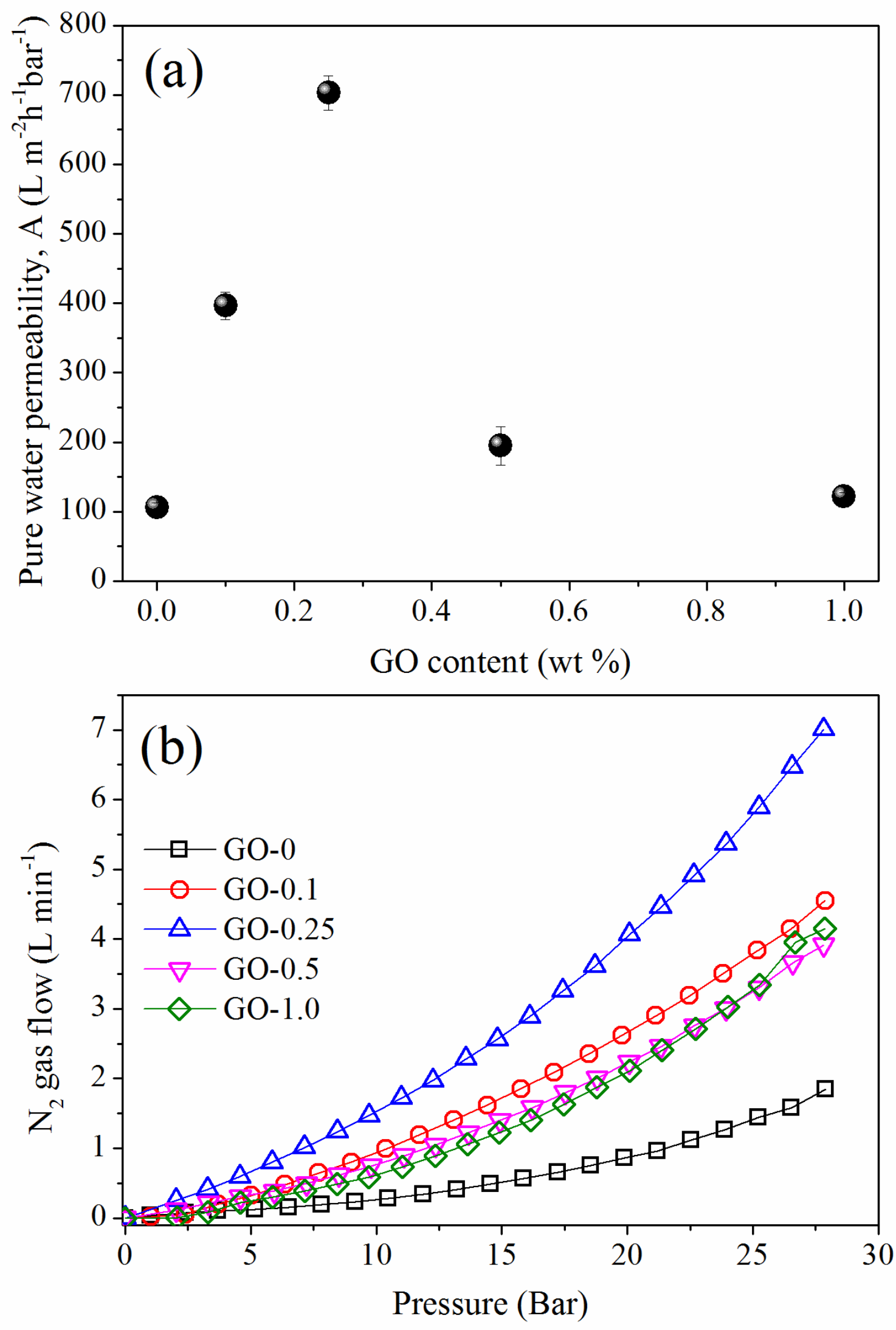

Figure 2 


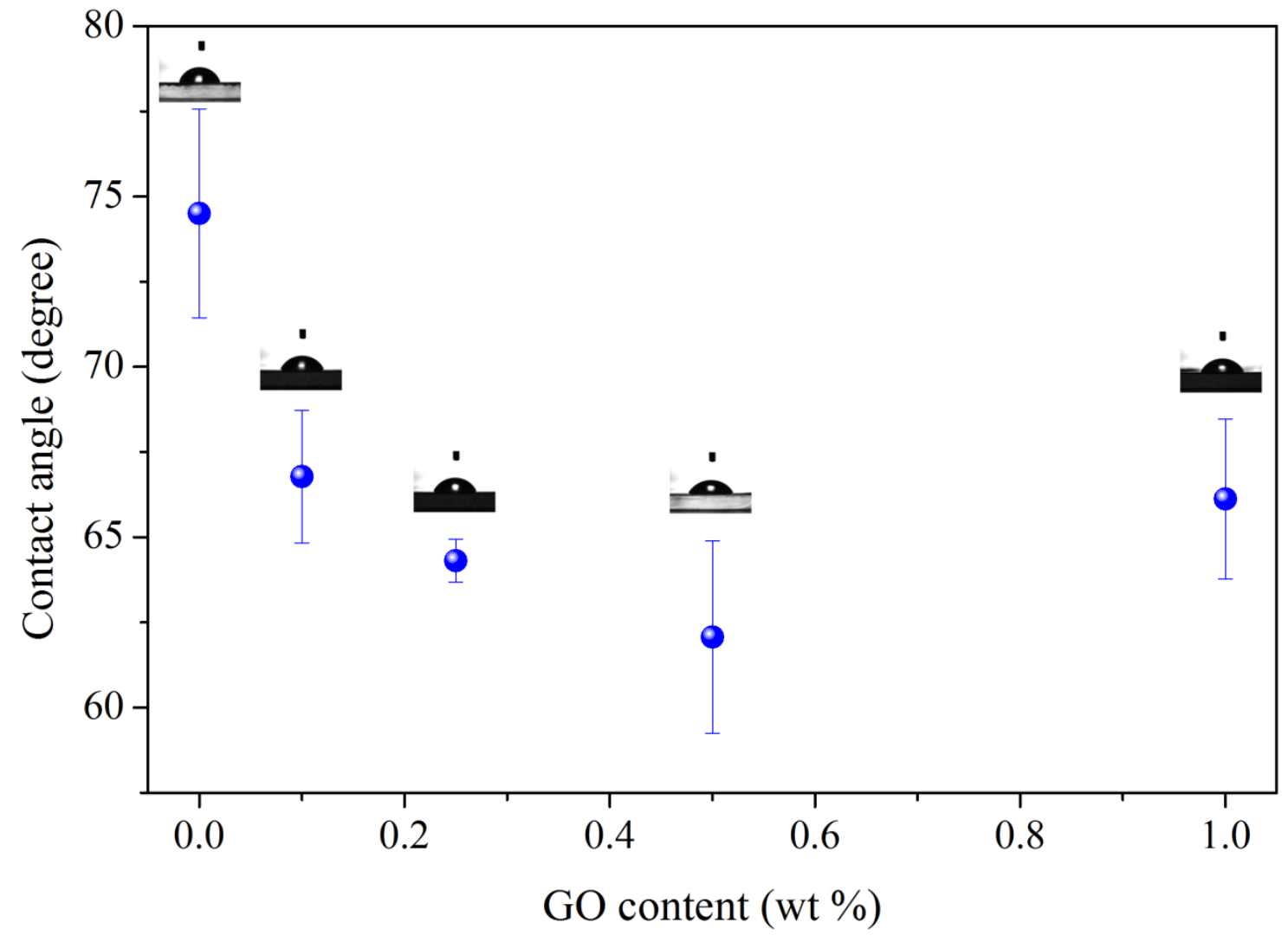

Figure 3 


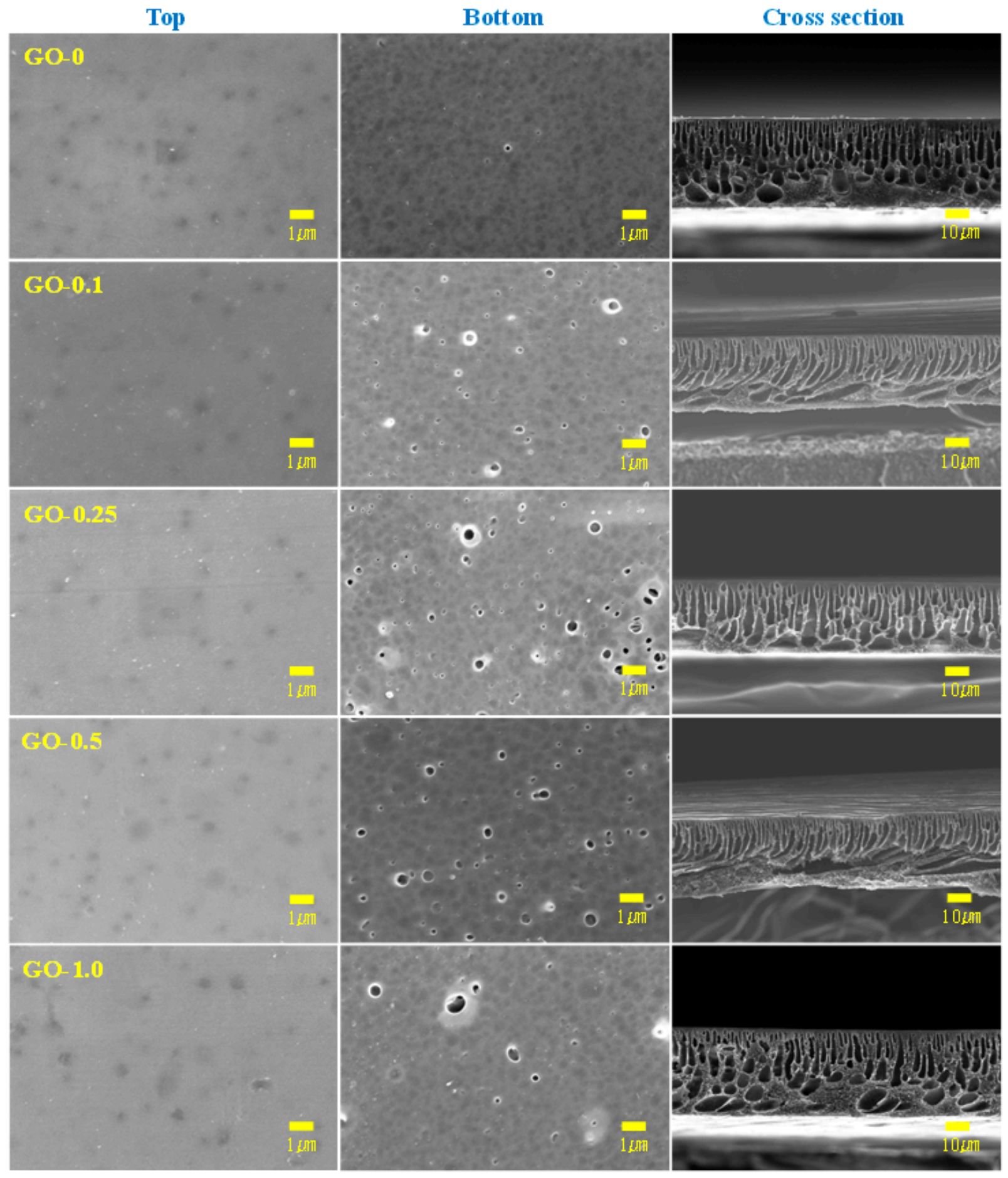

Figure 4 


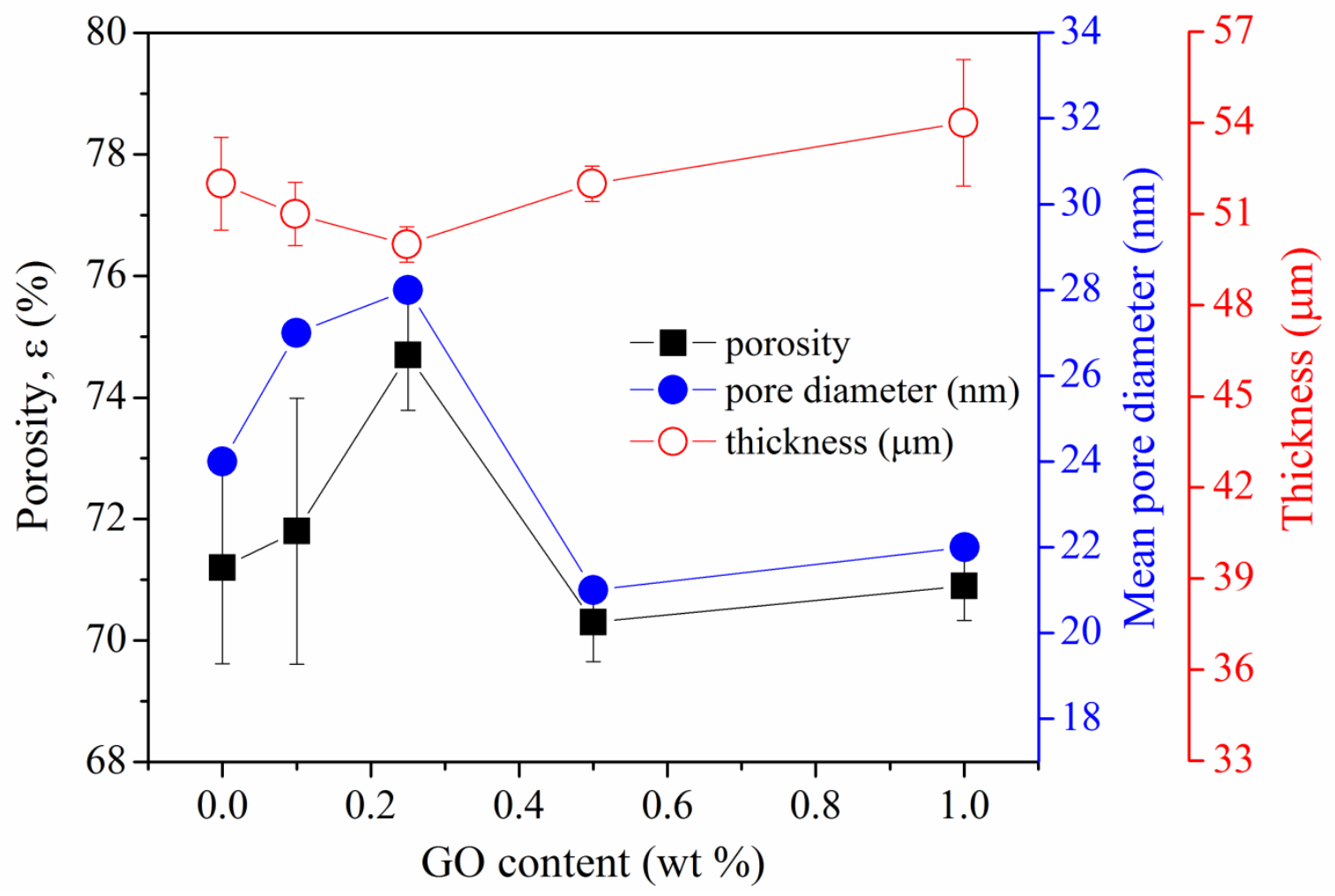

Figure 5

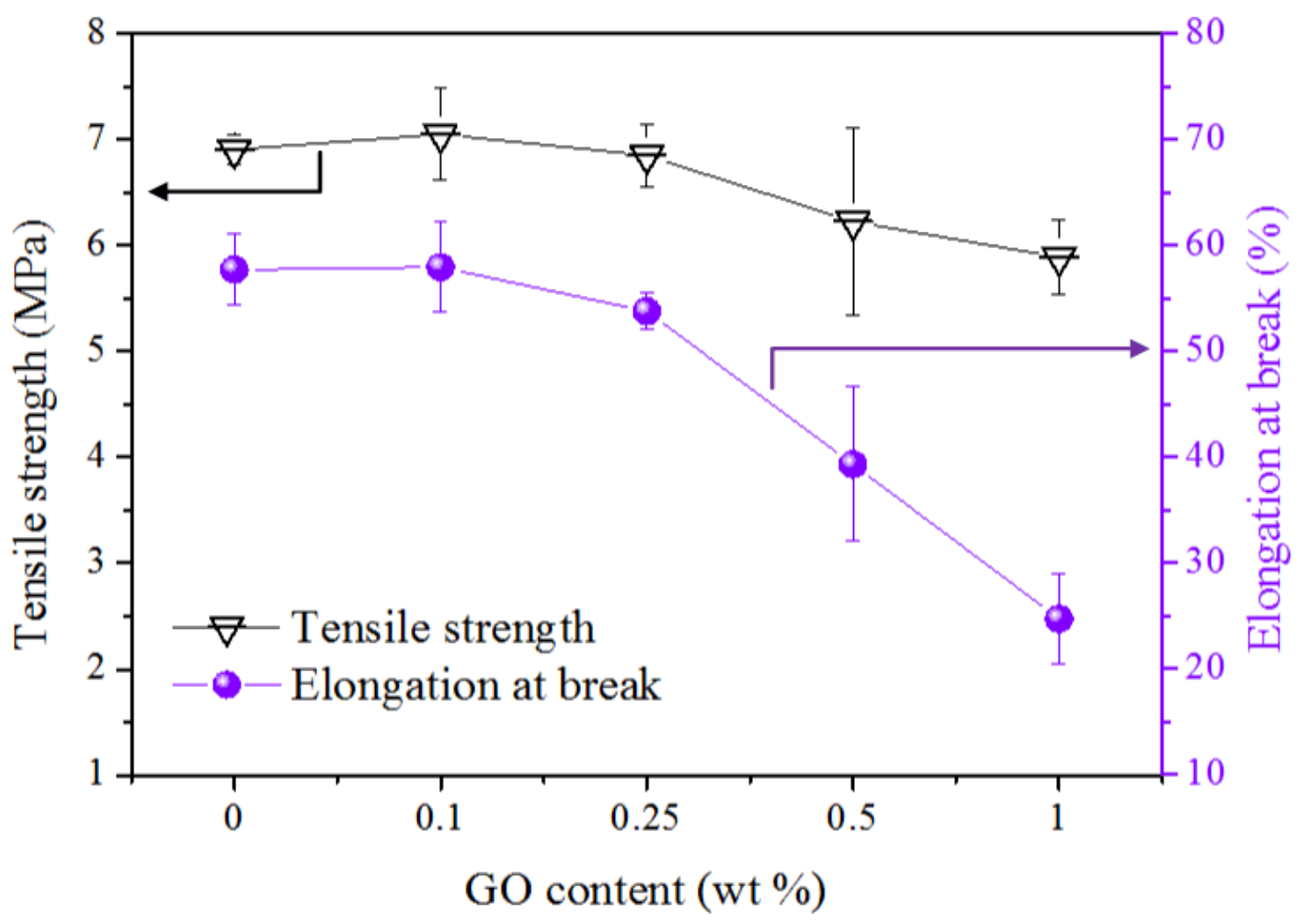

Figure 6 

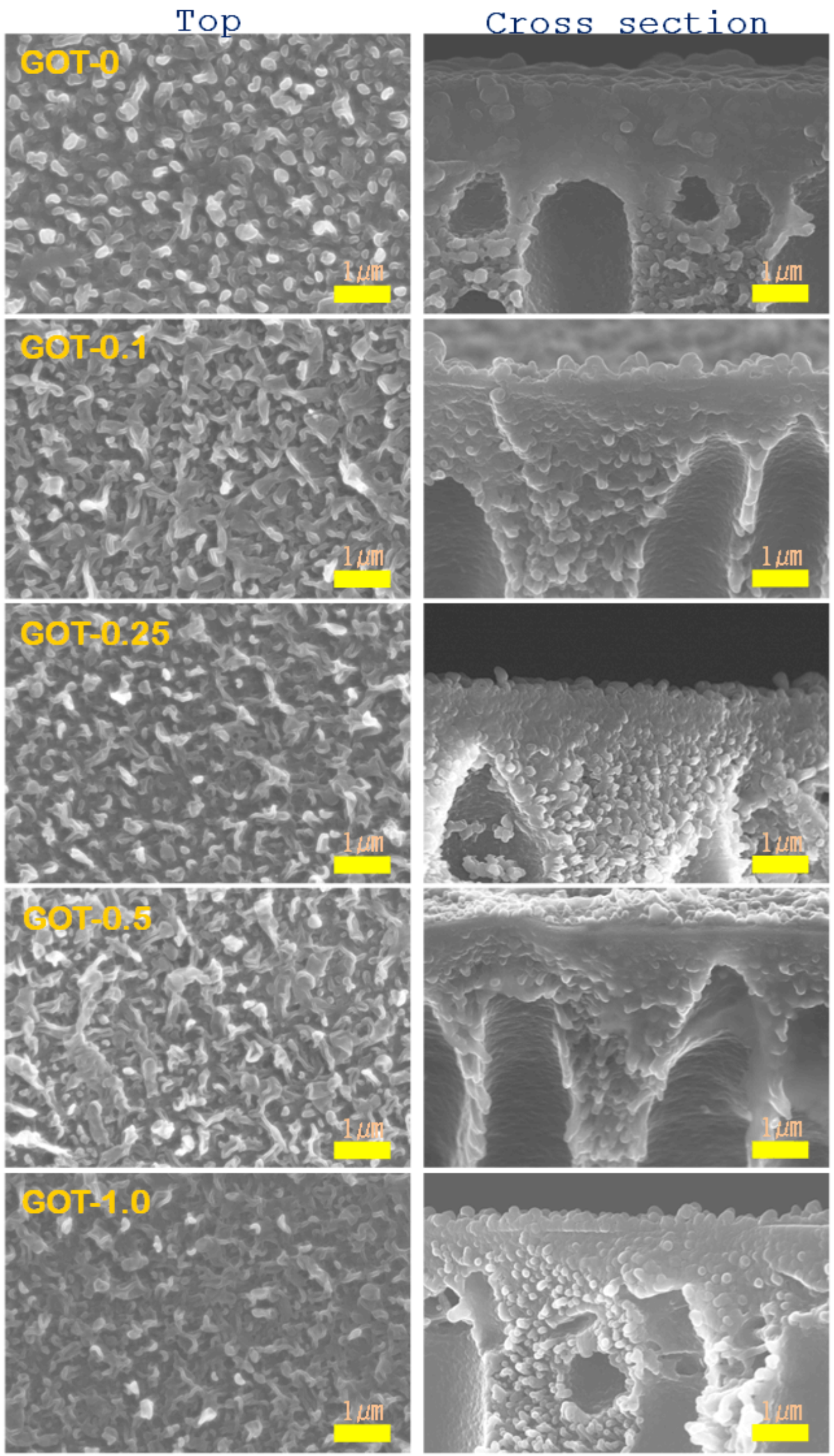

Figure 7 

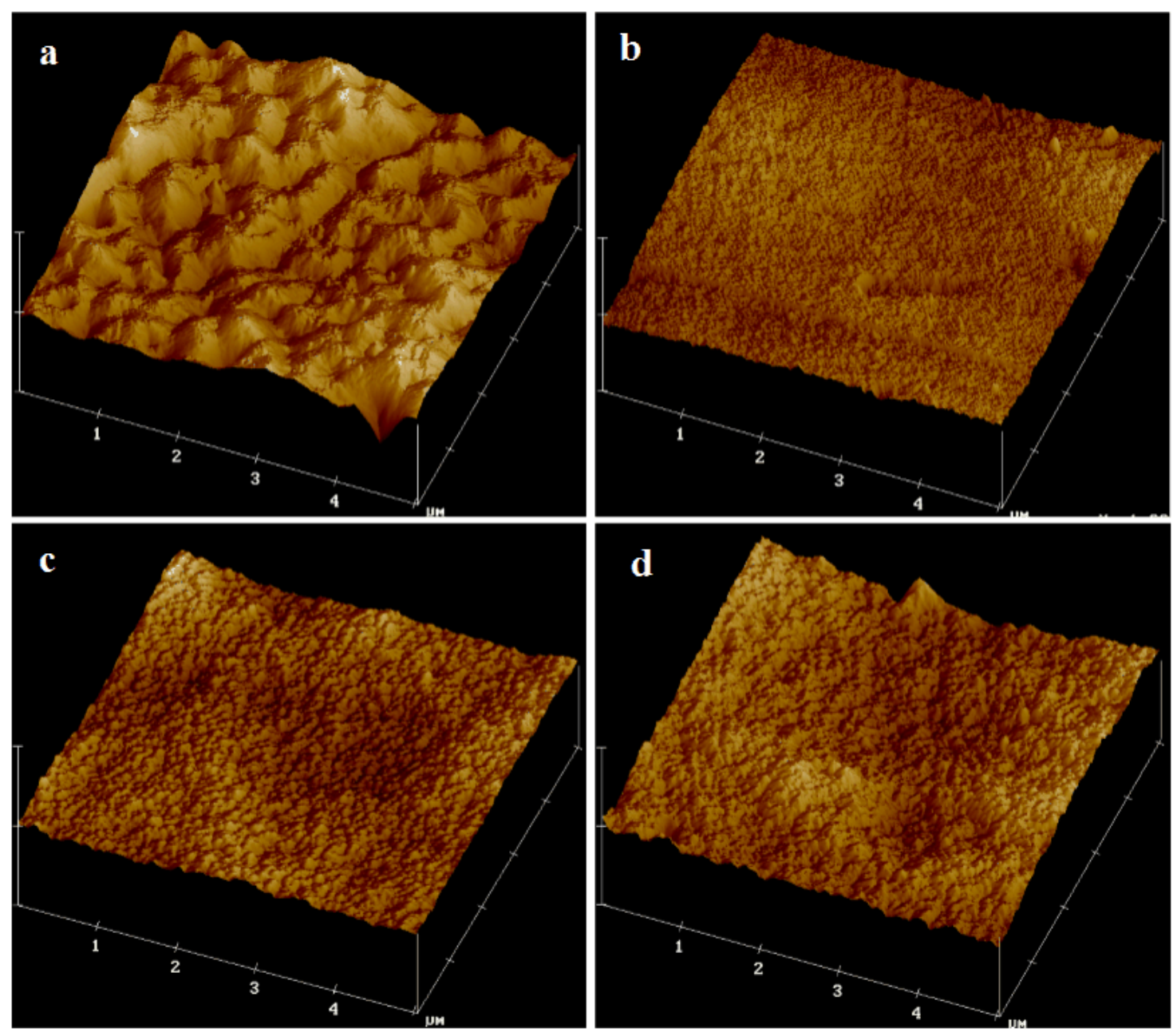

Figure 8 


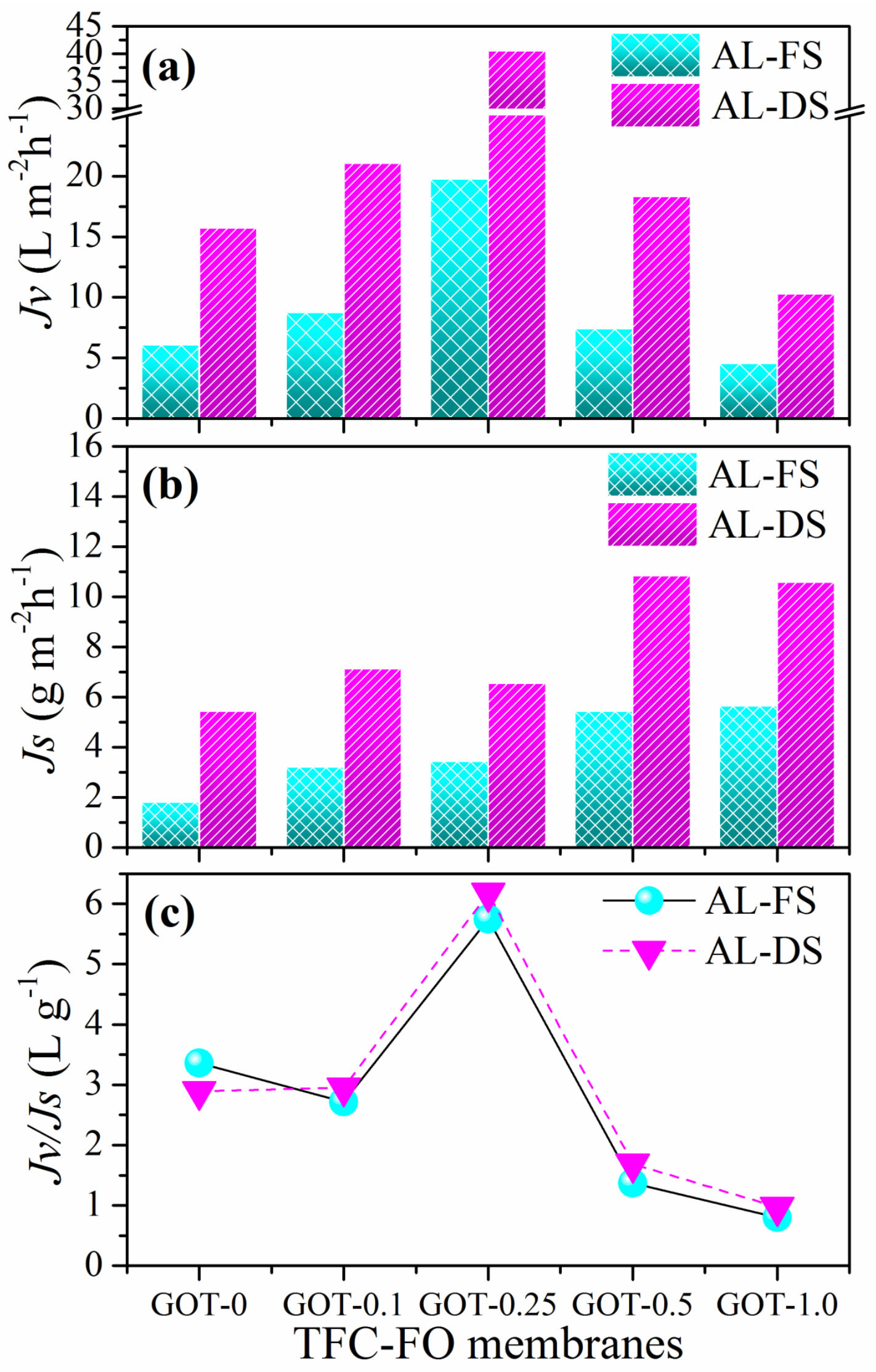

Figure 9 

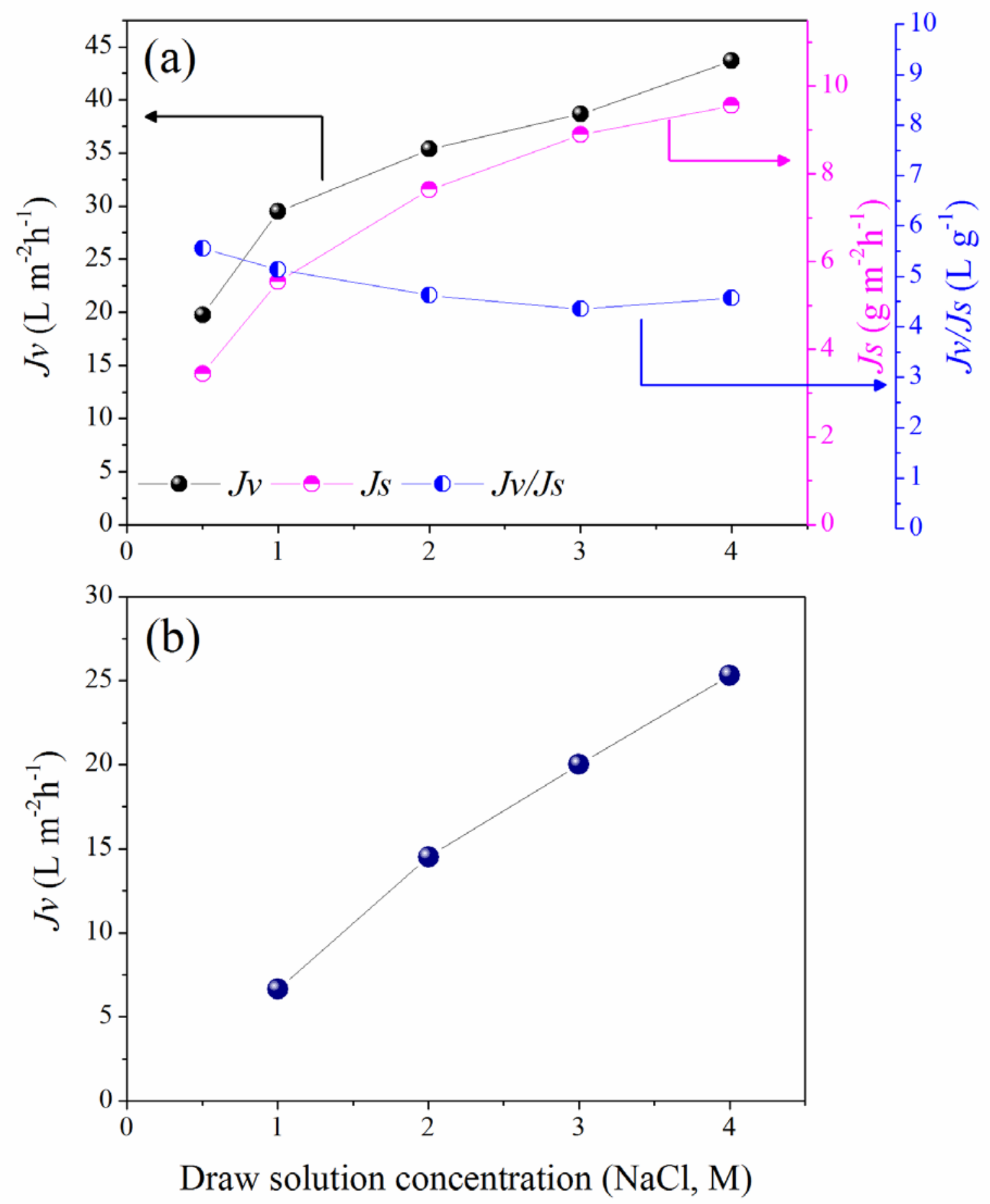

Figure 10 
Table 1

\begin{tabular}{lcccccc}
\hline $\begin{array}{l}\text { TFC-FO } \\
\text { membranes }\end{array}$ & $\begin{array}{c}A \\
\left(\mathrm{Lm}^{-2} \mathrm{~h}^{-1} \mathrm{bar}^{-1}\right)\end{array}$ & $B\left(\mathrm{Lm}^{-2} \mathrm{~h}^{-1}\right)$ & $B / A(\mathrm{bar})$ & $\mathrm{R}(\%)$ & $S(\mu \mathrm{m})$ & $\tau$ \\
\hline GOT-0 & 0.91 & 0.24 & 0.26 & 97.04 & 1060 & 14.51 \\
GOT-0.1 & 1.23 & 0.39 & 0.32 & 96.56 & 697 & 9.81 \\
GOT-0.25 & 1.76 & 0.19 & 0.11 & 98.71 & 191 & 2.85 \\
GOT-0.5 & 0.99 & 0.62 & 0.63 & 93.09 & 765 & 10.34 \\
GOT-1.0 & 0.91 & 0.91 & 0.99 & 90.09 & 1630 & 21.40 \\
\hline
\end{tabular}

Table 2

\begin{tabular}{lccc}
\hline Membrane substrates & $\mathrm{R}_{\mathrm{a}}(\mathrm{nm})$ & $\mathrm{R}_{\mathrm{ms}}(\mathrm{nm})$ & $\mathrm{R}_{\max }(\mathrm{nm})$ \\
\hline GO-0 & 14.09 & 17.56 & 30.45 \\
GO-0.1 & 6.75 & 8.56 & 15.27 \\
GO-0.25 & 6.48 & 8.26 & 12.97 \\
GO-0.5 & 8.03 & 9.76 & 17.25 \\
GO-1.0 & 7.97 & 9.48 & 17.06 \\
\hline
\end{tabular}

Note: $\mathrm{R}_{\mathrm{a}}=$ mean roughness, $\mathrm{R}_{\mathrm{ms}}=$ root mean square of $\mathrm{z}$ values, $\mathrm{R}_{\max }=$ maximum vertical distance between the highest data points 